\title{
House Rules: The Collaborative Nature of Policy in Domestic Networks
}

\author{
Andy Crabtree $\bullet$ Tom Rodden $\bullet$ Peter Tolmie $\bullet$ Richard Mortier $\bullet$ Tom Lodge $\bullet$ Pat Brundell $\bullet$ Nadia Pantidi
}

School of Computer Science, University of Nottingham, NG8 1BB, UK.

Email: (First name.Last name\}@ nottingham.ac.uk

\begin{abstract}
We draw on ethnographic studies to understand the collaborative nature of network policies or rules in domestic settings. We outline the technical nature of network policy in enterprise domains and how this contrasts with the social or collaborative nature of rules in everyday life. We then consider the deployment of network control and policy system interfaces in domestic settings, highlighting the ways in which household members collaboratively exploited these to support network governance. Our results suggest that an important feature of network policy in domestic contexts is that rules about network activity are shaped by and answerable to the moral reasoning that governs domestic life. This reframes our understanding of how rules are oriented to and used in the home and has significant implications for the design of home network policy systems.
\end{abstract}

Keywords Home networks, network policy and rules, moral order, collaborative interfaces, ethnography.

\section{Introduction}

Domestic wireless networks have become a mundane feature of a great many homes, routinely established by Internet Service Providers as part of the set up of broadband connections. Household activities are increasingly carried out through the network via multiple networked devices that populate the home. Media is increasingly consumed through the network; family communications are supported by it; everyday life is coordinated through it. A burgeoning range of activities are now predicated on and managed through the home network [5].

Despite the broad uptake of network systems in the home, there has been little effort on the part of industry providers to shape networking technology around user characteristics. Home networks consequently embody network management tools developed for enterprise that are "too complex for home users" [19]. Researchers have sought to reduce this complexity by (re)shaping network management around the distinctive characteristics of home users. For example, Yang et als Eden system (ibid.)

\footnotetext{
* This is the authors' version of the accepted manuscript. The final publication is available at Springer via http://dx.doi.org/10.1007/s00779014-0771-6
}

exploits a spatial metaphor to support network management, and Chetty et al. [4] developed Home Watcher to surface bandwidth usage and enable direct user control.

We wish to consider a topic which is implicit in these kinds of systems: network policy or the use of 'rules' to regulate and govern the home network. Network policies are an integral part of existing network infrastructures but they are also social and implicated in attempts to reshape network management for the home. The design of Eden and the 'internet restriction badge', for example, clearly implicates policy considerations, as does the 'etiquette' that emerged around the Home Watcher deployment. Curiously, however, neither study treats the topic of network policies or rules explicitly or in any depth.

This paper presents our experiences in shaping domestic policy interfaces and explicates the tension between user orientations to and understandings of 'network rules' and the enterprise orientations and understandings embedded in current home networking infrastructure. We briefly consider the nature of policy systems from an enterprise perspective, and the tools that have emerged to allow a range of prospective network policies to be written and subsequently enacted by the network [20]. We then report on the results from a range of ethnographic studies of the ways in which network rules are established retrospectively within domestic networks as an ongoing feature of the moral ordering of domestic life. We highlight the emergent and contingent nature of network rules and the extent to which users interpret and negotiate their occasioned use in a domestic context.

We address the inherent tension between the prospective enterprise view of network rules and the retrospective domestic view through two technology probes [11] that exploit services provided by our modified domestic router [12]. The probes provide two different kinds of interfaces for effecting network policy: one, the Comic Strip interface, which enables users to write network rules; and the other the Control Panel interface, which affords a means of network governance that "more closely mimics how households manage access and sharing with social relations and rules" [4]. The probes share strong similarities with the functionality provided by Eden insofar as they enable membership management, access control, network monitoring, and QoS policy. However, they reach out beyond the lab to understand network governance 'in the wild'. In this respect, the findings 
reported complement and extend those of Chetty et al. [4], moving beyond the politics of identity, representation and power to elaborate the underlying moral order that drives day-to-day governance of the home network.

We report on the deployment of network control and policy system interfaces, highlighting the ways in which household members exploited these to support network governance. Our results suggest that, in a domestic context, the rules of the network are understood to be inseparable from the rules of the house - that the rules governing one are directly implicated in the rules governing the other. The challenge, then, is one of understanding how the rules of the home might be articulated and used to define the rules of the network.

\section{The technical character of rules}

Rules or policies are a key feature of network systems. Indeed, the separation between policy and mechanism is widely used in distributed computer systems as a technique for simplifying complex problems into generic, widely applicable mechanisms and specific, contextdependent policies. Examples of mechanisms might include the weighted fair queuing discipline for providing quality-of-service in core routers; the BGP routing protocol through which the Internet is made into a connected network of networks; or the WPA2 standard for securely associating a device with an $802.11 \mathrm{Wi}-\mathrm{Fi}$ network. These mechanisms are deliberately neutral in how they might be used.

Policy, on the other hand, focuses on encoding how the network is intended to be used. Examples include deciding that real-time audio traffic should be protected from interference by web browsing traffic; that the Sprint network should be preferred to AT\&T's; or that your brother's laptop should be allowed to connect to your home network, but your neighbour's should not. Policies can be complex and multi-faceted, and depend on all kinds of features within and without the network. Distinguishing policy in this way permits the re-purposing of underlying software mechanisms without having to recode them.

Policies can be static, specified in advance and remaining in place until someone determines that the policy implementation needs modification; or adaptive, changing automatically in response to use and environmental features. Policies can be distinguished in a range of ways, e.g., by the roles to which they refer, the layer to which they apply, or the type of policy expressed. This has driven the development of a broad range of languages to express policy [20].

Specification of network policy in particular is closely related to the broader network configuration problem, where network devices (routers, firewalls, etc.) must all be configured consistently, both with each other and with the wider constraints of the network owner/manager. Configuration of this nature is complex, and misconfiguration leads to many, often globally visible, problems. As a result tools have been built that statically analyse network-wide configuration against a high-level policy specification [8].

All such policy specification is prospective, performed in advance of deployment, e.g., packets for a particular destination should be dropped; traffic matching a particular pattern should receive a particular quality-ofservice. Creating such specifications requires a high level of expertise: general understanding of the technology involved and the environment into which it is deployed, specific understanding of the problems to be dealt with and the aims of the deployment, and an ability to express the policy specification in the chosen tool. This places it clearly within a professional work context: experts carry out specification, observing and refining implementation.

As a result, it is professionally managed enterprise networks to which such tools are applied. These are largescale, geographically distributed, and often strive for homogeneity as a pragmatic way of reducing complexity. None of these features apply to the home network. Home networks are typically far smaller in scale (tens of devices, not thousands or more), exist within a restricted physical context, and are resolutely heterogeneous with new devices being continuously added in an ad hoc manner (from mobiles and games consoles to TVs, bathroom scales, etc.).

Network policies typically emphasise generic cases, foregrounding network traffic and device characteristics, with users being dealt with in terms of broad classes rather than particular individuals. Commercial products for managing home networks, such as Cisco Connect Cloud, continue to reflect this perspective even though they provide more usable interfaces. Our orientation to policy seeks to move away from a technical orientation to the network towards consideration of the ordinary activities that network use is embedded in and shaped by in the home.

Networks are an unremarkable feature of many homes and their management is now one of the domestic chores involved in running the household [16]. Household members have come to orient to the network as a mundane feature of everyday life and manage it as part and parcel of the ongoing social organisation of their ordinary domestic affairs [5]. The challenge here is one of understanding how this might be reflected in network policies - i.e., of understanding how we might exploit the rules ordering domestic life to govern the home network.

\section{The social character of rules}

Seen from a sociological perspective rules have been construed of as foundational to social organisation and 
order: through rules our individual behaviour is regulated and social order is created, maintained and reproduced. As Hilbert [9] puts it, "the idea that rules stabilise behaviour or that behavioural stability requires rules is a common-sense assumption of our time. As Rawls [14] points out, it is also wrong because "rules cannot tell you how to follow them ... that would entail an infinite regress." In short, one set of rules begets another and so on ad infinitum.

Rules cannot provide for social order then - they are not sufficient in and of themselves - and can instead be seen as an articulation of an underlying moral order that creates, maintains, reproduces and adapts rules and which gives them their force [6]. While it is tempting to view the moral order as being instantiated and reinforced through rules, which in turn produce the social order through their operation, infinite regress prohibits any such reduction. The analytic separation between social order and moral order is also fallacious: the moral order is the social order, the two are equivalent, one and the same (ibid.).

"When individuals confront moral reality, they are confronting society; society and morality are one and the same ... Morality is not simply an extrasocietal phenomenon attached to society that makes it run smoothly ... Absence of morality is absence of society ..." [9]

This means that if we want to understand rules and their role in the production of social order, we need to attend to the moral reasoning that articulates rules and which reflexively produces the social order in their articulation.

D. Lawrence Wieder provides an exemplary case in his seminal ethnographic study of the convict code in a halfway house [18]. While it is possible to render this code as a set of rules ordering resident behaviour (don't snitch, do not trust staff, show loyalty to other residents, etc.), residents could not recite the rule set. Rather, in practice, "the code" was locally employed by residents and staff to make sense of whatever was happening, and to make whatever was happening accountable to one another. As Wieder (ibid.) put it, "hearing the code and employing it as a 'guide to perception' gave behaviours of residents a specific and stable sense."

The upshot of this is that rules should not be treated as prescribing order but as devices invoked to account for order. Rules gain their sense from within the particular contexts in which they operate, and they operate to make the social order accountable to those who inhabit the settings in which they are manifest in, as well as to inquiring ethnographers. If we want to understand the sociality of rules then, we need to understand their accountable character and this will involve explicating the moral order that shapes the accountable use of rules in particular contexts. It is towards understanding the accountable character of rule use in the home and how this shapes network governance that we now turn.

\section{Understanding network rules in the home}

Our study of network rules in the home is part of a series of ongoing ethnographic studies of home networks initiated in 2009 and continuing to this day. The studies involve 24 households of enormously varied character, from families with younger and older children to single and shared occupancy households and from blue-collar to white collar and professional backgrounds. The studies are conducted through fieldwork [13] and involve informal interviews and direct observation with any and all household members (including children) who are willing to talk to us (and not all are). Fieldwork sessions are typically of 2 to 3 hours in duration, recorded on video and subsequently transcribed, and are conducted intermittently (every 3 to 6 months) and according to members availability and convenience to elaborate particular issues emerging from ongoing analysis.

In effect, the households provide us with a social network that we can contingently 'dip into' as occasion demands and 'drill down' into particular issues that interest us, as well as pool to draw on for deployments. One of the issues that interested us for design reasons was the topic of network rules. For other issues that have been treated during the course of these studies see, for example, $[3,5$, $8,15]$. The results of our studies of network rules, including re-examination of the materials that sparked our interest in the topic [10], are outlined below.

\subsection{Network rules are about people}

In the following examples we see that household members have a specific orientation to 'just who?' is using the network and that use is bound up with quite definite expectations about appropriate conduct.

Father: Ellie has some boundaries imposed upon her - the new regime is for the laptop to go outside the bedroom door at 9 o'clock.

Fieldworker: What happens if she breaks those rules?

Mother: We take it off her. The worst punishment is to take the laptop away from her.

Fieldworker: Has that happened?

Father: Yes, yes ... The rule is a recently re-imposed one. We had a conversation about the quantity of usage and the isolating effect of being online. It's very addictive. It's much more fun than being with your mouldy old parents. She's a 14 year old girl so whether she has a laptop in her room or not she would choose to spend a good deal of her time in her own space; really typical for a 14 year old. She's had her laptop for 2 years and before that had access to another machine but she wouldn't use it in her room. There were rules initially - we've let go a lot of those and possibly become too lax, hence the kind of reopening of a conversation.

No doubt a familiar conversation to a great many parents of teenagers, but the above vignette extends way beyond this to index the unexplicated ways in which members' orientation to 'just who?' is using the network, and all that is implicated in that question, shape and govern its use. 
'Just who?' is a subtle and nuanced matter. It may implicate moral concerns with good parenting and it may implicate a host of other moral concerns at work in the home. Here we see someone who runs his export business from home expressing concerns regarding the use of the network by his son, who works part of the time as a DJ:

With my activities - I mean if I only call off emails it doesn't take a lot unless I have large attachments - but I think Danny has no real concept of being economical in what he does ... If I don't use much data at the time then fine ... I don't really have any large requirements on film or music downloads. Danny's requirements are far larger than mine, but I don't want his to be so large that my relatively small data requirement becomes slow.

Another participant who also ran a business from his home put the basic concern here more bluntly:

I see myself as using the Internet to bring in income, so I can justify that pretty well everything that I do takes priority.

In both of these examples one might see the potential grounding of rules in accountable claims regarding whose use of the network should take precedence. However, in the first example you can also see that it's subtler than that. The householder in question has no problem with his son hogging the network if he's not using "much data at the time." So the reasoning here is also bound up with just what particular people are doing at particular times, something that is intrinsically contingent.

The infinite regress implicated in rule following means that it is simply not possible for formal rules to cover all contingencies. The distinction between a formal position and contingency extends to how household members' reason about other people on the network as both categories of people and living breathing individuals they actually know. This is particularly pronounced when we consider the reasoning implicated in giving external parties access to the network. One participant put it as follows:

You don't want it so your next-door neighbours could be able to get on for free onto the network.

Nonetheless, time and again throughout all of our studies we saw exceptions routinely being made for people who were actually known by the participants, and with a variety of entirely cogent situated accounts:

Our next-door neighbour is an old lady. Her daughter works at the university as well and she's in poor health so her daughter comes round a lot. l've given them access to the network as well so she can check her email and do a bit of work while she's here. I've no idea how often they access, l've just given them the key. It's invisible. I know it's not heavy - it doesn't impact. If the usage did get heavy I would put a new password on it and block them out. But as I can't see it it's not an issue ...

One of my friends came to visit with an iPhone and I have given them the password and that has been OK. I am not sure what sort of connection they have and they tend to manage that. Most people never ask for the password although I would be happy to give it to them ... I keep thinking about having one of these apps that would let me have an open guest network but I have never explored them much more than that.

Rules that encompass groups of people as certain kinds of identifiable categories might at first sight be seen to be a useful basis for defining policies. However, the question of 'just who?' is subject to a potentially endless series of refinements based upon moral matters to do with being a good host or good neighbour which implicate specific people with specific requirements that are difficult to predefine. The rules that shape network use - who is allowed on to it, when, for how long, and even what they do on it - are themselves shaped by a host of situationally contingent moral concerns revolving around the individuals that use the network and what it is appropriate for them to be doing at any particular time.

\subsection{Network rules are socially situated}

While oriented to by individuals rules are, nevertheless, socially situated. They are shaped by intersubjective relationships and concerns about being good parents, good hosts, good neighbours, etc. Rules are embedded in lively social arrangements and the lively character of these arrangements has consequences for how it is that we might think of specifying formal rules too. In a domestic context rules are rarely written down, instead being largely accomplished and brought to bear by means of talk and conversation. The following vignette elaborates the point:

Fieldworker: Do you have any rules in terms of using the network?

Thanh: Like in the evening, do not download too much. You can download but not too much.

Giang: If someone is downloading you are just gonna shout "Who is downloading?"

Fieldworker: Is it mostly when you play games that you want to make sure there is no downloading happening at the same time? Thanh: Sure!

Giang: Even Skype is off.

Thanh: When we play everyone turn off their download automatically, there is no problem. The problem is when sometimes people want to download a movie and others are not aware and it is slow.

Giang: Sometimes it is not too slow but sometimes it is really, really slow.

Fieldworker: Are there any usage rules in terms of your visitors and guests?

Giang: They can Skype, they can surf the web, they do whatever they want but I don't think they download.

Thanh: They don't download.

Fieldworker: What if someone was doing that, what would you do?

Giang: If it would slow it down, we'll tell them no.

Thanh: We tell them to stop.

The interaction that occurs during such events doesn't necessarily lead to the direct articulation of a rule. What it does do is make visible to members what kinds of activities others might call them to account for. This is usually enough to establish the grounds for telling people to stop doing things in the future, without having to expressly point to the presence of a rule.

Even when there is an express rule in place, members place moral value on the 'social touch', on making rules accountable, which impacts the devolution of formal rules to automatic systems: 
The problem for me with that is - if I say to Emma, "I don't want you going on the net after nine o'clock because that's when I want you to go to bed" - I could set it up that her computer just locks her out at nine o'clock, but there's a whole load of things about whether as a mother I should actually be going to her and speaking to her ...

Rules are not simply about enforcing conduct then. They are embedded in social relationships and situated in dialogue between relevant parties to a rule's use. What matters is not the rule as such but what the rule is intended to bring about within and as a constitutive feature of the ongoing social organisation of domestic life:

Father: Some period of time is negotiated for doing homework and we know that they haven't, so I go on the history and you know, "oh look for the whole time you said you were doing homework there's all this Facebook activity!" That tends to be the most part, there doesn't tend to be any kind of looking through history for anything more dubious.

Olivia: Mum has this thing - no computer for 2 hours while we're doing homework unless you need it.

Fieldworker: Are the rules followed?

Olivia: Sometimes (laughs).

Fieldworker: What happens if they're not?

Olivia: Mum's basically said "shut it down". Mum will just sneak up behind us (laughs) but we never get in that much trouble for mum to take away our phones or whatever.

As this vignette makes visible, blind obedience to the rule is not the point - the homework rule is occasionally ignored and it is known by Olivia's parents that it is occasionally ignored. The issue is not one of following the rule per se but of complying with the "negotiated" order, which results in homework being routinely accomplished. Clearly the rule does not enforce that. What provides for it is the ongoing negotiation between relevant parties to the rule's use. The vignette suggests that making residents aware of particular activity may be of greater value than automating formal rules, thereby providing resources to support the lively social arrangements and ongoing negotiation that rule use is embedded in.

4.3 Network rules are open to interpretation and negotiation

The socially situated and negotiated character of rules means that rules are open to interpretation and also to renegotiation. The contingencies of social life make it impossible to pre-specify the exact circumstances of a rule's application. Consequently, members find themselves labouring under a 'gambit of compliance' [2] and thus seeking to 'honour the spirit of the rule' [21] i.e., respecting what the rule is intended to bring about rather than respecting the rule per se.

The upshot of this interpretive work is that the actions carried out on any particular occasion might seem to stand in direct contradiction to formal articulations. Receiving guests and visitors provides a perspicuous example. In one of the households we studied both of the adults routinely worked at home as well as in their offices and their work activities on the network were typically oriented to as taking precedence. However, the moral order of the household also encompassed notions of having guests and being a good host when guests were present. This could lead to occasioned revisions of the general rule that 'work takes precedence':

One thing that I try to do is to schedule my work around them... if they are watching TV on their machine or using Skype I tend to back off from the network for a while and let them do that ...

It is tempting to see such events as exceptions to the rule but the moral order drives the continuous interpretation and application of rules in the face of contingencies:

Fieldworker: Are there other rules in the house? I know you've mentioned an evening meal no device use.

Mother: Yeah, nobody is allowed to use - generally - there's the occasional - but generally, nobody uses mobile phones.

Father: Not unless you're taking a phone call, no (laughs).

Mother: You see that's where it becomes unclear. If you're on the phone and then dinner's served then it's difficult to put the phone down and to start to eat.

Father: So you're saying it's alright for you to be on the phone (laughs) but no-one else.

Mother: Yeah, but on the whole we don't have devices at the table. We don't allow it.

Even in cases where we might expect rules to be rigidly applied, we find in practice that they are open to interpretation and renegotiation. We found in our studies, for example, that some parents try to pre-specify rules of Internet access for their children through systems such as NetNanny. What we uncovered, however, was a much more nuanced use of such rules with their application being regularly subject to renegotiation upon the pleading of their case by children:

As the kids got more into the Internet we kind of thought "yeah, we're not entirely sure what they're going to find, what they're going to browse" so we thought we'd install NetNanny. It's hard to be systematic about which sites you want to block and which ones you don't. It does take active control. So basically you've got a couple of options: you could go into the sites that NetNanny recommends by default, but it turns out that doesn't satisfy the kids. There are some things they want to look at that we are happy for them to look at that aren't on the list, so you can then either maintain the list of allowed and blocked sites yourself but you'd have to update that fairly regularly with a fair bit of discussion about each one or you end up saying "never mind all that, we'll log you in as 'grown up' mode." For us updating the list doesn't happen because it feels like just a bit too much hassle to do it. So when they log on, NetNanny will be set to kid mode and then if they want to look at something else they'll come to me and there'll be a bit of whingeing and they'll say "we hate Net Nanny, wurr-wurr-wurr" and then we'll decide whether to unblock it temporarily.

Thus, even in situations where rules are formally specified, their use is subject to ongoing revision.

\subsection{Network rules are retrospective}

When rules are formally specified in domestic life, not only are they rarely written down, being articulated in interaction and conversation, they are also and essentially retrospective in character. Rare exceptions to the written rule demonstrate the point: 
During the night's about the only time l'm ever certain of getting anything downloaded 'cause at any point in the day someone can answer the phone and kill it. If I have something downloading, you can get up to just about any point in it and then if someone answers the phone l've lost the whole download. I have to start again from the beginning. If I hear the phone ring it depends on the state of the download. If it's over $50 \%$ then it's already been running for quite a while and l'd prefer people didn't answer the phone, so I'll ask them not to. But if it's still only up to about $20 \%$ I don't bother. I also have a post-it-note by the telephone. Sometimes if I remember I try to stop people picking up the phone by physically sticking it on the phone. It reads "Do not answer. Download in progress."

Such inscriptions are not 'keep off the grass' notices, however, intended to express a general over-arching rule, but rather notices that have been placed where they are to remind people not to do specific things that have been done in the past which have produced negative results. The rule, while clearly oriented to future events, is based on retrospective experience that breaches the social order and which household members seek to avoid in the future.

Rules are shaped retrospectively rather than prospectively. Rule specification is almost always a consequence of some kind of breach, rather than something that members sit down and actively consider in advance. More than this, the terms upon which members are called to account with respect to rules rarely relate to 'good technical practice', but instead to how their actions might impact upon the social organisation of the home and its moral order. In the following example we see, for example, a general appeal being made to the availability of online access for all members of the household when it is undermined by the uploading of videos to YouTube by one of it's members:

Chloe: We have had big rows about Tim stealing the Internet Emma said to him "You've stolen the internet!" - 'cause he's uploading to YouTube and the whole thing just like grinds to a halt for everybody else. We have had to say, "You put it on overnight Tim when nobody else needs it."

Tim: Yeah, so normally I just upload overnight. And that's it. Normally what I do is if the video files are under 50 megabytes I upload it because it only takes 5 or 10 minutes, but normally if it's bigger than that I do it overnight.

The specification of the upload rule is the outcome of retrospective experience that impacts upon the social order and the moral concerns that shape it. It is designed to regulate an individual's conduct for the benefit of all household members, though it is not adhered to as a blanket policy, but rather one that can be applied in a nuanced way in relation to matters such as file size and the likely impact this will have on others' access to and use of the network.

Rules may also be imposed in light of retrospective experience to sanction individuals and enforce the moral order. In another example from the same household we saw rules being implemented to actively punish "bad" behaviour by one of the household members as well as to limit the possibility of it happening again:

She's on MSN but she's on a ban at the moment. She got into a scrap with a girl online which was a bit unhelpful. She is using the
Internet again but she's not allowed to go on MSN. She was getting involved in some cyber bullying and I had a concern that she was actually doing it, and I think she was about eleven or twelve at the time and just wasn't mature enough to walk away from it. So I stopped it because I thought she was actually the perpetrator. I just wanted to cut her off from that and stop it because I didn't want another child being hurt by her.

In discussions with householders about the remit of possible future deployments it became quickly apparent that they are perfectly well aware of the retrospective character of rule specification and use and were keen that systems be able to accommodate this:

One of my things has always been thinking about blocking access to certain things or certain types of things, and one of the problems is that it's a very difficult thing to do that in a nuanced way. It's like when is bad language gratuitous and when is it not. So if we said we don't want them to access websites where they use the $\mathrm{F}$ word there might well be things that are lost by that ... So you'd have to do it by website and say things like "Oh Sam you're not allowed to go to bloodandgore.com", so it would be reactive rather than proactive...

In short, rules are not specified in advance of their use but contingently to maintain the moral order of domestic life. They may be invoked for a wide variety of purposes but they are not pre-configured. Rather, they emerge and are applied in the ongoing production of social order. Their application is subject to contingency, interpretation and revision. They are socially defined and situated in relation to specific activities. They are member-centric, oriented in their application to specific individuals, and include specifications of temporal order.

\section{Supporting network rules}

Our study of network rules were conducted as part of a broader project that seeks to redefine domestic network infrastructure by reinventing the home router [12]. Network policy is an integral feature of home router design and our studies were both shaped by and in turn shaped our understanding of the topic. While informed by a particular 'value position' then, one that put emphasis on the need to reinvent network policy as part and parcel of the effort to re-engineer the home router around user characteristics, our studies were not drawn on to specify requirements for systems development. Rather, they sensitised the design team to the social nature of network governance and the moral ordering of network rules.

The design team responded to the issues raised by our studies by deploying interfaces to probe [11] the topic of network rules and to understand the potential to develop mechanisms that respect the social character of network governance. Thus, and for example, the interfaces developed to probe this topic enable parental control (much as Eden does) and surface network behaviour (much as Home Watcher does), but with the explicit goal of exploring the moral imperatives and social practices that shape and drive network use in the home and thereby enabling users to express their own 'value positions'. 

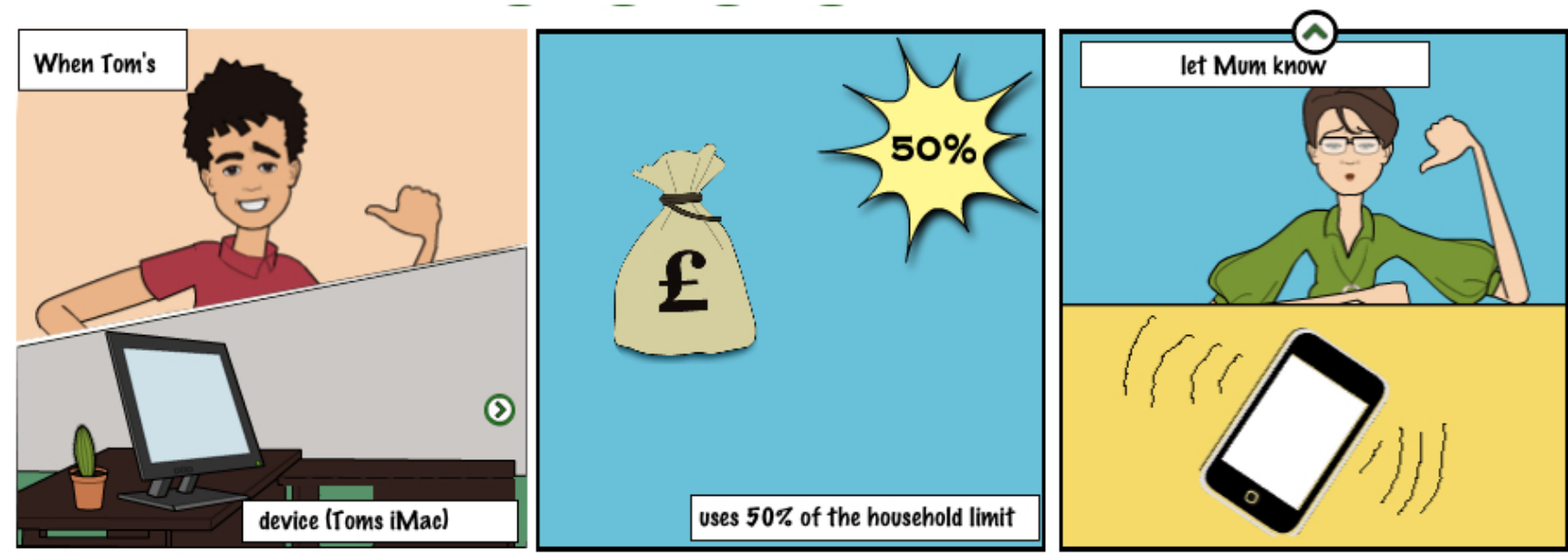

Figure 1. A policy notifying Mum when Tom has used 50\% of the home's download limit.

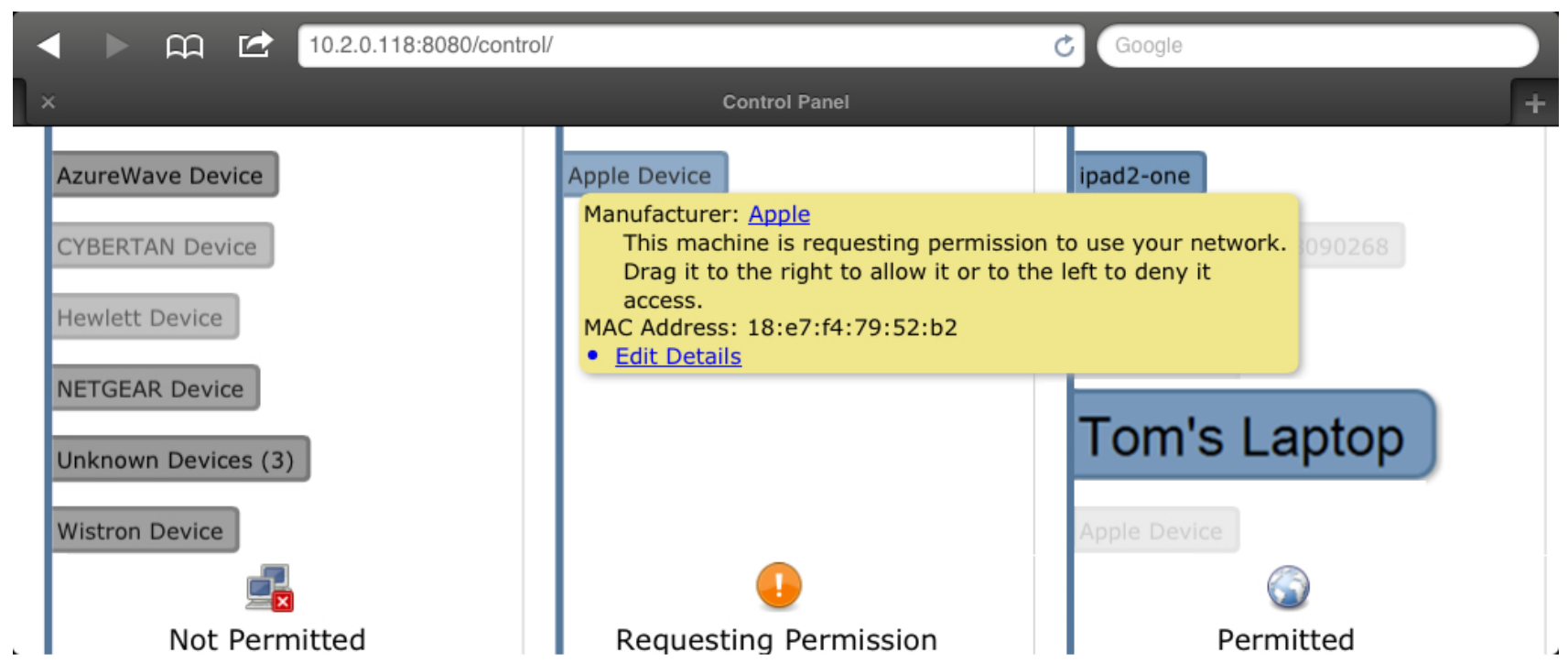

Figure 2. The control panel showing an Apple device requesting network connectivity.

Our home router monitors and controls networkconnected devices without requiring the installation of additional software on these devices. It also provides a distinct control API that lets us develop user interfaces to control traffic and devices on the network. These routers have been deployed within 5 of the homes participating in our ongoing studies for extended periods of time (between 3 and 6 months to date) and their use also studied through fieldwork. The period of deployment is required to transcend the novelty effect and allow sufficient time for the router to become an unremarkable feature of domestic life [17]. Two particular interfaces emerged as a response to our ethnographic studies of rules and were also released as part of the router deployment: the Comic Strip and Control Panel interfaces.

\subsection{The comic strip interface}

Drawing on the insights provided by the ethnographic studies we explored approaches to policy or rules that moved away from the traditional views of devices and traffic inherent in networking systems. We wished to foreground household members and their activities in the articulation of policies. Our main policy interface exploits the underlying mechanism in our infrastructure but focuses on users' reactions to network activities rather than the traffic on the network. Our vocabulary is deliberately not one of bandwidth and types of traffic or of the attribution of priority to control consumption. Rather our focus is on what people are doing on the network, who should be aware of this and what the potential consequences of these activities might be. Our interface takes the form of simple comic strips that convey what the network should do under particular circumstances. The aesthetic of the interface is chosen to 
be playful rather than overly task driven in an attempt to make policy specification and change a 'low overhead', 'easy-to-implement' activity [1].

Actions are specified in response to a range of factors, including time and date, bandwidth, device connection, and access to particular domains. Actions can be applied to specific devices, users or services (currently identified by their DNS name). Actions can range from simple recording of network state as collected by the router, to notification of individual's actions by some means (e.g., SMS, telephone, email), to direct control over a device's connectivity to the network or to particular services. Figure 1 depicts a simple notification policy, where mum is to be notified whenever dad is using a particular device to access the network. This form of notification policy focuses on prompting the social interactions and negotiations that shape network use.

\subsection{The control panel interface}

The policy comic strip was complemented in our deployments by a control panel that displayed the status of devices on the network. This control panel interface allowed devices to be added and removed from the network using a simple drag and drop gesture. For example, Figure 2 shows the control panel when a machine requests connection. The requesting machine appears in the central display panel. Any user with access to the display may then choose to drag any device to the right. Doing so invokes the web API on the router to mark the device (identified by MAC address) as 'permitted', granting it an IP address and enabling its traffic to be routed. Similarly, by dragging a device icon to the 'not allowed' region users can disconnect devices from the network. Connected machines' icons vary in size with the proportion of the bandwidth they are using and are highlighted when connection issues arise.

\section{Home network rules-in-use}

The control panel and policy system were deployed in 5 homes participating in our studies over a period of 3-4 months. These include 2 families with children living with them (aged between 8 and 18), 2 families whose children have left home, and a house shared by 4 students (aged between 19 and 25). During the deployment all the participating households reported "playing" with the policy system to explore its potential utility. However, only 2 out of the 5 households implemented and deployed rules via the policy system. The rationale as to why 3 out of the 5 households did not write rules reflects the real world, real time character of rules in a domestic context. As one participant put it, by way of example and elucidation,
"It relates to accessing sites as far as I can see it ... being notified that someone is using their computer when it is really just the two of us - I think these are more for a family."

In short, the formal specification and implementation of rules was understood by our participants as being something of relevance to "families", and by that they meant households with children, rather than households of shared occupancy (whether that be couples or members with no long-term relationship, such as the students). Thus, rules are in a strong sense perceived as being parenting devices and this orientation is inherited by networking policies. This is reflected in the two households that did specify and implement rules via the policy system. The policies expressed here focused on policing activities on the network. We draw on two examples, one from each household, to explicate the collaborative nature of network policy use and how household members orient to them.

\subsection{Example \#1. Managing the conduct of homework}

The first household consisted of two adults (male and female, aged 45 and 46 respectively) and two teenagers (both females, aged 17 and 18 respectively). Here the policy system was used to manage the conduct of homework. During the deployment phase the oldest daughter - Anna - was sitting the last of her exams for University entrance. Both Anna and her parents placed considerable value on her succeeding and thus implemented a rule via the policy system that blocked the Internet if she accessed Facebook or YouTube during daily revision hours between $12-3 \mathrm{pm}$ on weekdays. The rule is not an end in itself, but subordinate to higher-level social and moral goals. It was not imposed upon Anna by her parents but "negotiated" between them.

Fieldworker: So if you go on Facebook it blocks the whole Internet?

Anna: Yeah it does (laughs). You can't go on anything! I don't do it

at all now 'cause they tell me what times it's going to be blocked between and l'll just - I'll obviously use the Internet but not go on Facebook because what I was doing on the Internet that wasn't Facebook I want to be able to still do.

Father: There are occasions when we're out and about and we'll get a text or a call from Anna saying the "Internet's not working" (laughs) and "you're going to sort it out aren't you now" (laughs).

Fieldworker: But you can't sort it out until you get home?

Father: Well yeah, no.

Fieldworker: How do you feel about that Anna?

Anna: You get a bit annoyed, but it does help me so it's alright. It means that I actually have to do some work.

Even this seemingly blanket rule exhibits its own subtleties of use:

Fieldworker: Is it [applied at] the same times?

Anna: It's the same time for weekdays and then it depends during weekend. Sometimes I'm at work and then obviously I won't be planning to use it anyway so there's no point, but if I'm sat down and do work we'll arrange a kind of "if you're going to do work then we'll block it between now and whatever time".

What is also striking in this vignette is the intersubjective understanding of rules in the system. Anna and her 
parents understood the nature of the rule and how it was to be interpreted as part of a broader agreement. This shaped how the rule was oriented to as something that was for general guidance and open to re-specification as necessary. The above vignette also reinforces the need for flexibility in policy systems. In particular it suggests the need to allow remote access to and control of rules along with ready amendment of their temporal parameters. Addressing these issues involved providing secure access to the control API on the router to allow rules to be easily amended.

\subsection{Example \#2. Managing appropriate use of the Internet}

The second household consisted of two adults (male and female, aged 54 and 50 respectively) and two teenagers (one male and one female, aged 18 and 14 respectively). Here rule specification was driven by the parents' concern with age appropriate conduct:

Mother: We played with it and - 'cause Ellie [age 14] is almost too old now to need to be controlled - it was more like "Ellie's on Facebook", and you'd call up the stairs "are you on Facebook?" but we haven't set up a complex set of rules. I think if they were a bit younger I might have done. I might have thought of a way to stop them using the Internet after a certain point in time.

Here a rule was specified that notified the mother by SMS message if her daughter accessed the Internet after 9pm. Again, this policy was intended to reinforce a higher-level rule: that Ellie be in bed by $9.30 \mathrm{pm}$, which was understood to mean in bed as asleep, not tucked up in bed playing around on Facebook, or browsing the web.

Fieldworker: So if you went to bed and were on Facebook?

Ellie: Mum would just come up and say like "what are you still doing up, you're supposed to be like heading bedwards."

The use of rules lies not simply in their application but in their being made accountable. Thus, the aim here is not, as in the previous example, to simply block access but to notify others of an individual's behaviour to enable them to take appropriate action: in this case to enable Ellie's mother to reinforce the $9.30 \mathrm{pm}$ bedtime rule. The responsibility for enacting the rule is not derogated to an automatic policy but seen and treated as something that needs to be carried out in person. Essentially, applying the rule is understood to be part and parcel of good parenting. As one of our participants previously put it,

... there's a whole load of things about whether as a mother I should actually be going to her and speaking to her ...

For Ellie's mother, enforcing the bedtime rule in person is also one of those things that she feels she should be going and speaking to her daughter about. Nonetheless, she quickly changed the method of notification.

It [SMS notification] drove me nuts for about an hour so I stopped that and it emailed me if Ellie went in Facebook.

This switched the mode of notification from constant push to user-driven pull and emphasises the need for designers to consider not only the mode of notification but also the frequency of notification.

\subsection{Example \#3. Managing the no download rule}

That rules were only formally specified or 'written' in households with children does not mean that our other participants had no interest in rules or found no utility in our interfaces. By way of example and elaboration, one of our deployments was in a student household that had a broadly understood "no download" rule when they were playing online games. However, the rule was not something the household members wished to formally encode:

Giang: I haven't started using the comic policy yet.

Thanh: 'cause we don't have any special policies ...

Vuong: We are not really using that because we think that might be somehow affecting the privacy of some people, so we let it like that, so everyone can connect to anything they want.

The moral order at work in this home - in which all members have equal claim to network access - prohibits the formal specification of rules. The writing of rules was seen as impacting the independence of individual members. However, even though it remained unwritten the "no download" rule was actively managed, but rather than use the policy system to articulate and enforce it the gamers instead used the control panel. This enabled them to see which machines were on the network and how much bandwidth they were consuming, thus supporting the no download rule.

Vuong: If the Internet is slow and we don't know who is downloading anything, instead of going to everyone's door and asking if they are downloading anything we just look - "OK, that guy is using a lot of network, kick him out!" (Everyone laughs).

Fieldworker: That's a bit different - last time you were describing how you would go to everyone's room to check if they are downloading.

Thanh: Yeah.

Vuong: Yeah, yeah, ask "are you downloading anything" and they would say "no, no, not downloading anything", but the network is very slow! Now you don't have to wait to know the truth (everyone laughs).

Fieldworker: So now when you see on the iPad that someone you find out who is downloading or using, what do you do? Do you still go knock on their door or do you stop them from here?

Vuong: One touch here and then move here (mimics taking a device completely offline via the control panel) and that's it.

Fieldworker: Have you been doing this?

Vuong: No, I am just joking, just joking (everyone laughs).

Giang: I think because we are friends here ...

Vuong: That is not a problem for us. We are very close friends here, so yeah. In case of another house, four people from different places that live in the same house, that might be a problem if one has the control of the network. In our case it will be fine.

Giang: I think it is, you know - here we have some limitation, we don't really have the right.

In place of formally specifying rules, members instead used the control panel as a device that surfaced relevant activity and enabled them to infer at-a-glance if anyone was in breach of the no download rule. The control panel provided a passive means of notification engendering awareness of activity that supported surreptitious monitoring. It is also notable that the control panel was not used to remotely implement the no download rule - 
downloaders were not "kicked out" off the network. Instead, the awareness of activity provided by the control panel supported existing interactional practices of bringing the rule about. Again, this was shaped by the moral ordering of the home and the shared view amongst its members that no one has the "right" to kick someone else off the network.

\section{Reflecting on domestic network rules}

Our experience of deploying the policy system and control panel has highlighted the need to marry mechanistic enterprise perspective on rules as they are understood and executed within the infrastructure with social understandings of rules within the home. This separation highlights a number of issues that are critical for the developers of policy systems for domestic use to appreciate.

\subsection{Policy specification and the moral/social order}

The social nature of rules is such that they are intimately linked to the particular social character of a home. It is clear from our studies that not all homes desire to specify rules. The interleaving of domestic activities and networking activity means that formal network rules essentially provide an articulation of what is deemed to be permissible. This does not necessarily suit all households and it is important to reflect on general applicability of network policy, as the formal specification of rules was used by households to manage specific activities and behaviours on the network.

This arrangement aligns best with homes where clear statements of allowable and expected behaviour is the norm. This is a common practice in family settings and in particular in the practice of parenting where the setting and negotiating of rules features strongly in the moral ordering of domestic life. In family households written policy essentially becomes a parenting device. The writing of policy rules within the system is not about regulating network activities and behaviours per se, however, but higher-level matters such as completing homework or going to bed at a certain time, which are the primary object of household members' moral reasoning and reflexively constitute the social order of the home.

\subsection{Network policy lives in the home not the network}

Given the history of network policies in enterprise settings it is easy to think of all network policies as being about the network and as things living within it. What is clear from our studies and deployments is that for the domestic setting, the policy lives in the social life of the home rather than in the network. What we mean by this is that the expression of polices within the network is part of a larger framing of rules surrounding network use. Network policies are indexical to a set of local understandings and agreements within the home. They are consequently read and understood by users in this social context.

This means that policy mechanisms need to recognise and support the essentially negotiated character of rule use in the home. This is particularly important when we consider how network rules are enacted in the home. Rules are not enacted entirely by the networks and impact upon much more than the network and devices connected to it. Simply derogating rule enactment to machines would breach the moral order of the home then. We would suggest that it is therefore necessary to think of policy systems in terms of human completion of rule application and to support the subtleties of rule use occasioned by contingency.

\subsection{Many policies will remain unwritten}

A final observation is that for many households, network policies will remain unwritten. These households are likely to be concerned about the impact of writing down policies on the relationships within the home. However, rules do not necessarily require formal specification for their use. In these cases it is more useful to convey awareness of network activities that are relevant to rule use, enabling members to surreptitiously monitor what is happening in the environment and take appropriate action. Surfacing relevant activities recognises the limits of formal specification. The specification and use of formal rules is constrained by the moral order and the concomitant extent to which members have the "right" to impose rules upon one another. In the absence of such rights, it would appear that surfacing activity would suffice to bring rules into play.

\section{Conclusion}

We have presented an exploration of network policy in domestic settings, highlighting the ways in which network rules need to be understood as inherently social phenomena that are irremediably tied to the moral ordering of domestic life and conduct within the home. We have drawn upon a series of ethnographic studies to elaborate the point and frame design explorations of alternative approaches to network policy which enable users to configure network policies around the ongoing and evolving moral ordering of day-to-day life in the home.

Our work suggests that explicit specification of network policies is at present most appropriate in family homes, where it can provide demonstrable support for 'parenting'. This situates network policy in a subservient relationship to social action and makes it accountable to the changing values and demands involved in raising children and managing their day-to-day conduct. However, we anticipate that the increasing network 
complexity - the adoption of more and more networked devices and services in the home, the increasing connectedness between homes and between homes and service providers, along with the growing trade in personal data - will drive broader need to enable user specification of network policy beyond the demands of parenting.

This will, in turn, require further significant reengineering of network infrastructure to make the network accountable to users and to enable user control. The Homework router [12], which enabled our explorations of user-driven network policy specification, is but one of an initial series of 'first steps' towards opening up the network and making it's workings visible to end users and amenable to their control. Moving forward it is critical that network developers understand the inherently socio-technical nature of the network, and that re-engineering efforts are closely coupled to empirical understandings of the social-cum-moral ordering and management of domestic life.

\section{Acknowledgements}

RCUK EP/F064276/1, EP/F064225/1, EP/F064446/1.

\section{References}

1. Bauer, L., Cranor, L., Reiter, M. and Vaniea, K. (2007) "Lessons learned from the deployment of a smartphone-based access-control system", Proc. of SOUPS, pp. 64-75, Pittsburgh, ACM.

2. Bittner E. (1965) "The concept of organisation", Social Research, vol. 32, pp. 230-55.

3. Brundell P. et al. (2011) "The network from above and below”, Proc. of SIGCOMM W-MUST, pp. 1-6, Toronto, ACM.

4. Chetty M., et al. (2010) "Who's hogging the bandwidth?", Proc. of CHI, pp. 659-668, Atlanta, ACM.

5. Crabtree A., et al. (2012) "Unremarkable networking", Proc. of DIS, pp. 554-563, Newcastle, ACM.
6. Durkheim, E. (1933) The Division of Labour in Society, Free Press.

7. Feamster N. and Balakrishnan H. (2005) "Detecting BGP configuration faults with static analysis", Proc. of the $2^{\text {nd }}$ NSDI Symposium, pp. 43-56, Boston, USENIX.

8. Grinter R.,et al. (2009) "The ins and outs of home networking", $A C M$ ToCHI, vol. 16 (2), Article No.8.

9. Hilbert R. (1992) "The status of rules in moral life", The Classical Roots of Ethnomethodology, pp. 27-45, University of North Carolina Press.

10. Hughes, J., et al. (1994) "Moving out of the control room", Proc. of CSCW, pp. 429-438, Chapel Hill, ACM.

11.Hutchinson, H., et al. (2003) "Technology probes: inspiring design for and with families", Proc. of CHI, pp. 17-24, Fort Lauderdale, ACM.

12. Mortier R., et al. (2012) "Homework: putting interaction into the infrastructure", Proc. of UIST, pp. 197-206, Cambridge, ACM.

13. Randall, D., Harper, R. and Rouncefield, M. (2007) Fieldwork for Design: Theory and Practice, Springer.

14. Rawls A. (2002) "Editor's introduction", Ethnomethodology's Program, pp. 1-64, Rowman \& Littlefield.

15. Rodden, T., et al. (2009) "Homebase", Proc. of CHI, Workshop on Home Behaviour Datasets, Boston, ACM.

16. Tolmie P., et al. (2007) "Digital housekeeping", Proc. of ECSCW, pp. 331-350, Limerick, Springer.

17. Tolmie, P. and Crabtree, A. (2008) "Deploying research technology in the home", Proc. of CSCW, pp. 639-648, ACM.

18. Wieder D.L. (1974) Language and Social Reality, Mouton.

19. Yang J., Edwards K., and Haslem D. (2010) "Eden", Proc. of UIST, pp, 109-118, New York, ACM.

20. W3 Policy Language Review, www.w3.org/Policy/pling/wiki/PolicyLangReview

21.Zimmerman D. (1970) "The practicalities of rule use", Understanding Everyday Life (ed. Douglas J.D.), pp. 221-238, Aldine. 